\title{
Estimation of Prevalence of Musculoskeletal Pain \& Rheumatic Disorders in a Rural Community of Bangladesh
}

\author{
Md. Moshiour Rahman ${ }^{* 1}$, AKM Mazharul Islam², Md. Mostafizur Rahman², \\ Md. Rafiqul Islam ${ }^{4}$, Dilruba Yesmin Liza ${ }^{5}$, Md. Golam Kibria ${ }^{6}$
}

\section{Abstract}

Introduction: Rheumatic disorders are one of the largest health problems in the world both in developed \& developing countries. They are the most common causes of chronic health problems and long term physical disability, work loss and loss of income. The study was conducted among the 15 plus years aged people in selected areas based on broad objective of exploring the prevalence of rheumatic disorders. Materials and Methods: It was an Observational cross sectional study. The study was conducted among the people of nineteen small villages of Sonargaon upazilla in Narayanganj district, Bangladesh. This study was conducted From January 2010 to December 2011. All subjects of the defined area aged $\vec{\partial} 15$ years were included in this study. Results: The point prevalence rate of definite rheumatic disorders was $23.7 \%$. Age, sex and occupations were associated with the overall prevalence rate. The prevalence was higher (51.8\%) in older aged (65years and above) population. Females (34.5\%) were affected more than males (18.6\%) in this rural area. Conclusion: These diseases are associated with some form of disability and work loss, as well as loss of income. More community-based studies with the design for the identification of associate's factors for individual rheumatic disease are needed. So that appropriate messages can be given to the community for prevention and treatment of rheumatic disorders.

Keywords: Prevalence, Rheumatic disorders, Rural community.

Number of Tables: 06; Number of Figures: 02; Number of References: 07; Number of Correspondence: 03.

*1. Corresponding Author:

Dr. Md. Moshiour Rahman

Associate Professor

Department of Medicine

Patuakhali Medical College, Patuakhali.

Email : drmdrahman76@gmail.com

Mobile: 01717-860246

2. Dr. AKM Mazharul Islam

Associate Professor

Department of Medicine

Patuakhali Medical College, Patuakhali.

3. Dr. Md. Mostafizur Rahman

Senior Consultant

Department of Pediatric

250 Beded General Hospital, Patuakhali.

4. Dr. Md. Rafiqul Islam

Assistant Professor

Department of Medicine (Gastroenterology)

Patuakhali Medical College, Patuakhali.

5. Dr. Dilruba Yesmin Liza

Upazila Health \&Family Planning Officer Mirzagong, Patutakhali.

6. Dr. Md. Golam Kibria

Medical Officer

250 Beded General Hospital, Patuakhali.

\section{Introduction:}

Musculoskeletal disorders are common and disabling but are low priorities for public health resources and medical education curricula (Dequeker et al., 2000) ${ }^{2}$. In the world much effort has directed at killing diseases, whereas crippling diseases are relatively neglected and yet the social and economic burden which the later imposes is probably greater.

Prevalence studies for musculoskeletal pain and rheumatic disorders were performed in different western countries and data for major rheumatic disorders are available (Badely et al., 1994) ${ }^{1}$ (Reyes-Liernea et al., 2009)3. But for giving emphasis on rural communities in developing countries, WHO \& International League of Association for Rheumatology (ILAR) jointly founded the Community Oriented Program for Control of Rheumatic Disorders (COPCORD) in 1981. Primary objective of the COPCORD is reduction of community burden of rheumatic disorders, particularly in developing countries (Chaimnuay et al., 1998) ${ }^{4}$. COPCORD has played a crucial role in collecting data on rheumatic complaints and disability in rural areas especially in developing countries. The epidemiological studies of rheumatic diseases by WHO-ILAR-COPCORD have already been performed in urban and rural Filipinos (Dans LF et al., 1997) ${ }^{5}$, in rural \& urban Indonesians (Darmawan J et al., 1992) ${ }^{6}$, And in many others country all over the world. These studies denote the prevalence of musculoskeletal pain has varied from $11.6 \%$ to $45.5 \%$.

The Point Prevalence estimates of musculoskeletal pain in rural, urban slum and affluent urban communities were 26.2\% (women $31.3 \%$, men $21.1 \%$ ), $24.9 \%$ (women $27.5 \%$, men $22.6 \%$ ), and $27.9 \%$ (women $35.5 \%$, men $18.6 \%$ ), respectively was reported by COPCORD study group of Bangladesh. The overall point prevalence of musculoskeletal pain was $26.3 \%$ but the point prevalence of definite rheumatic disorders was $24 \%$ (S. A. Haq et al., 2005) ${ }^{7}$. In Bangladesh commonest rheumatic disorders were osteoarthritis of the knees, nonspecific low back pain, lumber spondylosis, fibromyalgia and soft tissue rheumatism. Their prevalence estimates were $7.5 \%$, $6.6 \%, 5 \%, 4.4 \%, 2.7 \%$ respectively, in the rural, $9.2 \%, 9.9 \%, 2.0 \%$, 
$3.2 \%$ and $2.5 \%$, respectably, in the urban slum, and $10.6 \%, 9.2 \%, 2.3 \%, 3.3 \%$ and $3.3 \%$ in the urban affluent community (S. A. Haq et al., 2005) ${ }^{7}$. There were large differences between different communities in the prevalence of pain at any site and of different rheumatic disorders. This difference may be attributed to differences in customs, habits, occupation and living conditions, but may also arise, at least partly, from differences in the methodology, adopted operational definitions and classification of symptoms or diseases.

To determine exactly, the socio-demographic characters, prevalence rate and disability burdens of musculoskeletal pain and rheumatic disorders in Bangladesh it is necessary to collect authentic data from the rural community, so that appropriate preventive measures can be taken to prevent and control the rheumatic morbidities. The population of Sonargaon upazilla of Narayangonj district was selected for community study. For effective supervision, quality control, reduction of cost, as well as compare with previous study the same rural area near Dhaka city was selected for the study.

\section{Objectives}

To estimation the prevalence of definite rheumatic disorders in a rural community and also try to search the socio-demographic factors associated with the rheumatic disorders of the study population.

\section{Materials and Methods:}

It was an Observational cross sectional study. The study was conducted among the people of nineteen small villages of Sonargaon upazilla in Narayanganj district, Bangladesh. This study was conducted From January 2010 to December 2011. All subjects of the defined area aged $\tilde{\partial}$ 15 years were included in this study.

Inclusion criteria are subjects of both sex aged oे 15 years were included in this study.

Exclusion criteria are critically ill patients (such as stroke, severe respiratory failure, unconscious patients), mentally handicapped persons (mental defect congenital or acquired preventing or resisting a person from participating in normal life or limiting their capacity to work) and relatives of the residents who had come to visit the study area for short period.

\section{Data Processing}

After collecting data were checked thoroughly for constancy and completeness. Data were checked to exclude any error or inconsistency.

\section{Statistical Analysis}

All analysis was done by appropriate statistical methods using spss are software for windows.

\section{Ethical Issues}

All ethical issues, which were related the research involved with human subject were followed according to the guideline of ethical review committee.

\section{Sample Size}

Sample size was calculated by using the following formula- $\quad \mathrm{N}=\frac{\mathrm{Z}^{2} \mathrm{pq}}{\mathrm{d}^{2}}$

Here,

$\mathrm{N}=$ required sample size

$Z=95 \%$ Confidence interval (1.96)

$\mathrm{P}=$ Prevalence or proportion of occurrence of rheumatic diseases in rural area $26 \%(0.26)$

$\mathrm{q}=100-\mathrm{p}$ or proportion of person not affected by the disease, $74 \%(0.74)$

$\mathrm{d}=$ Acceptable (allowable) error, 10\% of P, 2.6\% (0.026)

So, sample size was 1093(one thousand ninety-three). We considered $10 \%$ dropout, so approximate sample size was 1202 , rounded up to 1200 (one thousand two hundred).

NB: As prevalence studies all subjects in nineteen villages, aged 15 and more than 15 years were included for this study.

\section{Sampling Technique}

Sampling was done on the basis of some predetermined idea or subjective judgment. Here study area and study population was prefixed. Field workers with the supervision of the investigator identified persons with musculoskeletal pain by using culturally adapted and validated modified Bengali version of COPCORD questionnaire. Sample was enrolled on the basis of inclusion and exclusion criteria.

\section{Observations and Results:}

Total 5005 study subjects were selected for the study. Among them, 4850 (male-2447, female- 2403) were interviewed giving and here total response rate $96.9 \%$. Out of 4850 respondents, musculoskeletal pain and rheumatic disorder positive respondents were 1283 (male-454, female-829) and total Positive respondents rate $26.45 \%$. Male positive respondents rate $18.55 \%$ and female respondents rate $34.92 \%$. Rheumatic Disorder positive rate is higher among female then male (Fig.1).

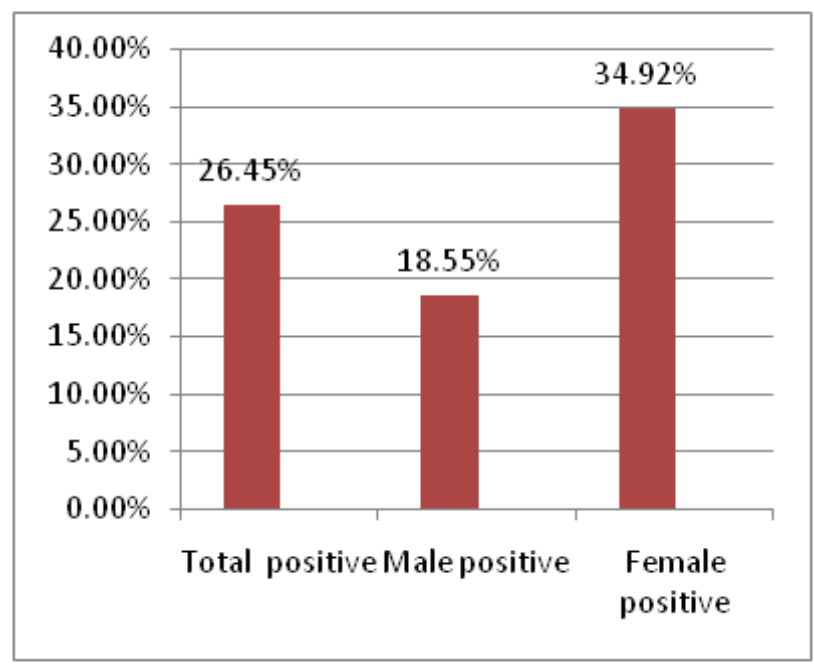

Figure-1: Prevalence of rheumatic disorders. 
Prevalence of positive respondents by age group and sex:

The distribution of positive respondents by age group and sex is shown in table-I

Table-I: Point prevalence of musculoskeletal pain by occupational group.

\begin{tabular}{lcccc}
\hline \multirow{2}{*}{ Occupation } & \multicolumn{2}{c}{ Interviewed population } & $\begin{array}{c}\text { Positive } \\
\text { respondents }\end{array}$ \\
& Number & Percent & Positive & Percent \\
\hline Students & 638 & 13.2 & 38 & 5.9 \\
Cultivators & 116 & 2.4 & 46 & 39.7 \\
Service (in door) & 195 & 4.0 & 18 & 9.2 \\
Retired persons & 229 & 4.7 & 86 & 37.6 \\
Housewives & 1850 & 38.1 & 688 & 37.2 \\
Day Laborers & 63 & 1.3 & 24 & 38.1 \\
Workers & 442 & 9.1 & 60 & 13.6 \\
Weavers & 667 & 13.8 & 186 & 27.9 \\
Garments worker & 56 & 1.2 & 7 & 12.5 \\
Drivers & 44 & 0.9 & 8 & 18.2 \\
Rickshaw/Van driver & 13 & 0.3 & 8 & 61.5 \\
Businessmen & 400 & 8.2 & 55 & 13.8 \\
Tailors & 16 & 0.3 & 4 & 25.0 \\
Others & 121 & 2.49 & 55 & 45.45 \\
\hline
\end{tabular}

The prevalence of musculoskeletal complaints increased with the increase of age. It was $12.6 \%$ in the aged group $15-24$ years and $51.8 \%$ in 65 years and above aged group (table-II).

Table-II: Prevalence by age group and sex distribution

\begin{tabular}{lcccccc}
\hline \multirow{2}{*}{ Age Group } & \multicolumn{3}{c}{ Interviewed population } & \multicolumn{3}{c}{ Positive respondent } \\
& Male & Female & Total & Male & Female & Total \\
\hline $15-24$ & $741(30.2)^{\#}$ & $766(31.8)$ & $1503(31.0)$ & $60(8.1)$ & $130(17.0)$ & $190(12.6)$ \\
$25-34$ & $671(27.4)$ & $618(25.7)$ & $1289(26.6)$ & $117(17.4)$ & $166(26.9)$ & $283(22.0)$ \\
$35-44$ & $442(18.1)$ & $441(18.4)$ & $883(18.2)$ & $93(21.0)$ & $191(43.3)$ & $284(32.2)$ \\
$45-54$ & $272(11.1)$ & $276(11.5)$ & $548(11.3)$ & $68(25.0)$ & $164(59.4)$ & $232(42.3)$ \\
$55-64$ & $197(8.1)$ & $177(7.4)$ & $374(7.7)$ & $62(31.5)$ & $103(58.2)$ & $165(44.1)$ \\
$65+$ & $124(5.1)$ & $125(5.2)$ & $249(5.1)$ & $54(43.5)$ & $75(60.0)$ & $129(51.8)$ \\
Total & 2447 & 2403 & 4850 & 454 & 829 & 1283 \\
\hline
\end{tabular}

\#Data in the parentheses indicate percentage

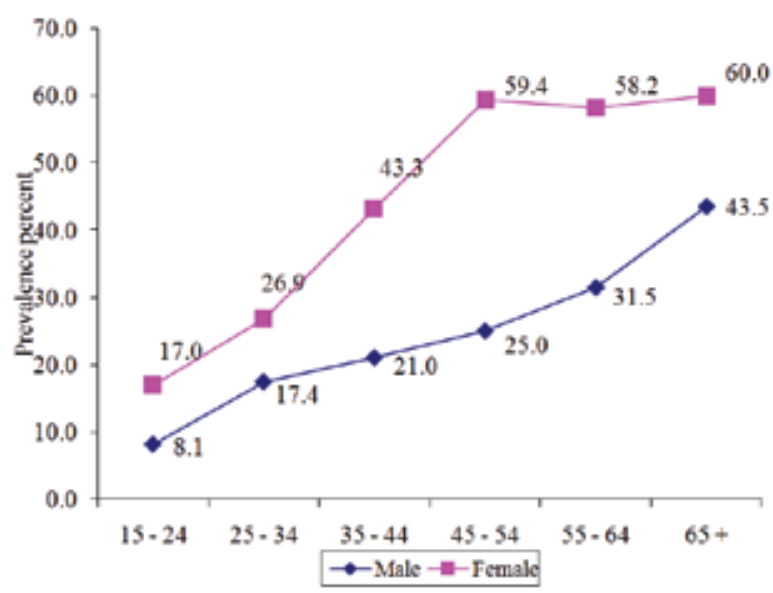

Figure-2: Prevalence of musculoskeletal pain by age group and sex.
Prevalence of musculoskeletal pain by occupation:

By occupation the prevalence of musculoskeletal pain was more common among the Rickshaw/Van drivers, cultivators, day laborers, retired persons and housewives. The prevalence of rheumatic pain was $61.5 \%, 39.7 \%, 38.1 \%$, $37.6 \%$ and $37.2 \%$ respectively among rickshaw/van drivers, cultivators, day laborers, retired persons and housewives (table -III).

Table-III: Prevalence of major rheumatic diseases by occupations.

\begin{tabular}{lcccc}
\hline Occupations & $\begin{array}{c}\text { OA Knee } \\
(\%)\end{array}$ & $\begin{array}{c}\text { LBP } \\
\text { (\%) }\end{array}$ & $\begin{array}{c}\text { Lumber spondylosis } \\
\text { (\%) }\end{array}$ & $\begin{array}{c}\text { Fibromyalgia } \\
\text { (\%) }\end{array}$ \\
\hline Student & 0.31 & 1.88 & 0.00 & 0.94 \\
Cultivator & 17.24 & 5.17 & 4.31 & 1.72 \\
Sales person & 1.54 & 1.54 & 1.54 & 0.00 \\
Retired persons & 23.14 & 3.49 & 9.17 & 2.18 \\
Housewife & 13.14 & 11.24 & 2.81 & 2.27 \\
Day Laborers & 15.87 & 4.76 & 1.59 & 0.00 \\
Worker & 3.17 & 3.85 & 0.45 & 1.58 \\
Weaver & 1.80 & 10.49 & 0.90 & 1.95 \\
Garments worker & 0.00 & 3.57 & 0.00 & 0.00 \\
Rickshaw/Van driver & 3.51 & 5.26 & 0.00 & 1.75 \\
Business & 1.75 & 4.00 & 1.25 & 1.75 \\
Others & 12.04 & 7.41 & 2.78 & 3.70 \\
\hline
\end{tabular}

The frequency of musculoskeletal pain was $19.0 \%$ in the smokers and $47.8 \%$ in the tobacco leaf users (table-IV).

Table -IV: Prevalence of musculoskeletal pain by habit:

\begin{tabular}{lcccccc}
\hline \multirow{2}{*}{ Habit } & \multicolumn{3}{c}{ Interviewed population } & \multicolumn{3}{c}{ Positive respondent } \\
& Male & Female & Total & Male & Female & Total \\
\hline \multirow{2}{*}{ Smoking } & 546 & 21 & 567 & 102 & 6 & 108 \\
& $(22.3)^{\#}$ & $(0.9)$ & $(11.7)$ & $(18.7)$ & $(28.6)$ & $(19.0)$ \\
Tobacco leaf & 183 & 369 & 552 & 73 & 191 & 264 \\
& $(7.5)$ & $(15.4)$ & $(11.4)$ & $(39.9)$ & $(51.8)$ & $(47.8)$ \\
Others & 19 & 6 & 25 & 5 & 1 & 6 \\
& $(0.8)$ & $(0.2)$ & $(0.5)$ & $(26.3)$ & $(16.7)$ & $(24.0)$ \\
Total & 2447 & 2403 & 4850 & 454 & 829 & 1283 \\
\hline
\end{tabular}

\#Data in the parentheses indicate percentage

Table-V: Frequency by Economic status.

\begin{tabular}{lcccc}
\hline \multirow{2}{*}{ Social status } & \multicolumn{2}{c}{ Interviewed population } & \multicolumn{2}{c}{ Positive respondents } \\
& Number & Percent & Positive & Percent \\
\hline Upper class & 228 & 4.7 & 56 & 24.6 \\
Middle class & 714 & 14.7 & 187 & 26.2 \\
Lower class & 3908 & 80.6 & 1040 & 26.6 \\
Total & $\mathbf{4 8 5 0}$ & & $\mathbf{1 2 8 3}$ & \\
\hline
\end{tabular}

Economic status of the positive respondents:

The frequency of MSK pain was $24.6 \%, 26.2 \%$ and $26.6 \%$ respectively in upper, middle and lower class (table-VI). 
Table-VI: Prevalence of MSK pain and rheumatic diseases.

\begin{tabular}{lcccc}
\hline Name of diseases & $\begin{array}{c}\text { Male } \\
(\mathrm{N}=\mathbf{2 4 4 7})\end{array}$ & $\begin{array}{c}\text { Female } \\
(\mathrm{N}=\mathbf{2 4 0 3})\end{array}$ & $\begin{array}{c}\text { Total } \\
(\mathrm{N}=\mathbf{4 8 5 0})\end{array}$ & $\mathbf{9 5 \%} \mathrm{CI}$ \\
\hline RA & $4(0.2)^{\#}$ & $28(1.2)$ & $32(0.7)$ & $0.47-0.93$ \\
SSA-AS & $20(0.8)$ & $25(1.0)$ & $45(0.9)$ & $0.69-1.24$ \\
SSA-PSA & $0(0.0)$ & $2(0.1)$ & $2(0.04)$ & $0.01-0.15$ \\
Reactive arthritis & $1(0.04)$ & $3(0.1)$ & $4(0.1)$ & $0.03-0.21$ \\
OA other than knee & $44(1.8)$ & $74(3.1)$ & $118(2.4)$ & $2.04-2.91$ \\
OA-Knees & $106(4.3)$ & $275(11.4)$ & $381(7.9)$ & $7.13-8.65$ \\
Fibromyalgia & $36(1.5)$ & $52(2.2)$ & $88(1.8)$ & $1.48-2.23$ \\
Frozen Shoulder & $2(0.1)$ & $11(0.5)$ & $13(0.3)$ & $0.16-0.46$ \\
STR & $41(1.7)$ & $61(2.5)$ & $102(2.1)$ & $1.74-2.55$ \\
SR-UBP & $37(1.5)$ & $37(1.5)$ & $74(1.5)$ & $1.22-1.91$ \\
SR-LBP & $115(4.7)$ & $249(10.4)$ & $364(7.5)$ & $6.80-8.28$ \\
VS (No specific disease) & $55(2.2)$ & $81(3.4)$ & $136(2.8)$ & $2.38-3.31$ \\
VSR-PIVD & $6(0.2)$ & $14(0.6)$ & $20(0.4)$ & $0.27-0.64$ \\
VSR-Radiculopathy & $1(0.04)$ & $9(0.4)$ & $10(0.2)$ & $0.11-0.38$ \\
TRM & $19(0.8)$ & $12(0.5)$ & $31(0.6)$ & $0.45-0.91$ \\
Total (MSK pain) & $454(18.6)$ & $\mathbf{8 2 9 ( 3 4 . 5 )}$ & $1283(26.5)$ & $25.23-27.71$ \\
\hline
\end{tabular}

* Multiple responses

\#Data in the parentheses indicates percentage.

\section{Discussion:}

This was an observational cross-sectional study to explore the musculoskeletal pain and rheumatic morbidity in the populations aged $\geq 15$ years in the nineteen small villages of Sonargaon upazilla of Narayangonj district. This study was conducted in two phases. The screening phase was conducted by eight trained field workers and examination phase by eight physicians including two rheumatologists. The response rate during screening and examination phases were $96.9 \%$ and $96.8 \%$ respectively.

The point prevalence rate of musculoskeletal pain was $26.5 \%$. The prevalence of definite rheumatic disorders was $23.7 \%$ and the remaining $2.8 \%$ had no identifiable musculoskeletal syndrome. Age, sex and occupations were associated with the overall prevalence rate. The prevalence was higher $(51.8 \%)$ in older aged (65yers and above) population. Females $(34.5 \%)$ were affected more than males $(18.6 \%)$ in this rural area. The commonly affected occupational groups were rickshaw/van drivers, cultivators, day laborers, retired persons and housewives respectively. The highest prevalence was recorded in lower class and then middle and upper class respectively. Among positive respondents tobacco leaf users were more frequently affected.

The most common site of pain of the body was low back (21\%) followed by knee (14\%), shoulder (7\%), hip (7\%), and ankle (6\%). OA knee $7.9 \%,(95 \%$ CI 7.13-8.65) was the most frequent rheumatic disease identified in the rural population followed by low back pain $7.5 \%,(95 \%$ CI 6.80-8.28) OA other than knee $2.4 \%,(95 \%$ CI 2.04-2.91), STR $2.1 \%$, (95\% CI 1.74- 2.55) fibromyalgia 1.8\%, (95\% CI 1.48- 2. 23) and upper back pain $1.5 \%(95 \%$ CI $1.22-1.91)$. Rheumatoid arthritis was found in $0.7 \%$ of the population and others inflammatory arthritis were uncommon. Females were affected more frequently than males in all cases.

Functional disability in various forms was identified among positive respondents and only few of them had complete inability to do specific tasks. Nineteen percent of rheumatic patients had work loss with a mean duration of 18 days in the preceding 12 months among positive respondents. Majority of positive cases commonly used NSAIDS or analgesic for relieving pain with or without prescription.

\section{Conclusion:}

Rheumatic diseases are common in the Bangladeshi rural community. The study revealed wide spectrum rheumatic diseases of which degenerative and mechanical diseases were the main group of disorder. These diseases are associated with some form of disability and work loss, as well as loss of income. More community-based studies with the design for the identification of associate's factors for individual rheumatic disease are needed so that appropriate messages can be given to the community for prevention and treatment of rheumatic disorders.

Conflict of Interest: None.

Acknowledgment: This study was conducted by self-funded.

\section{Bibliography:}

1. Badley EM, Rasooly I, Webster GK. Relative importance of musculoskeletal disorders as a cause of chronic health problems, disability and health care utilization: Findings of 1990 Ontario Health Survey. J Rheumatol. 1994; 21: 505-14.

2. Dequeker J, Rasker JJ, Woolf AD. Educational issues in rheumatology. Baillieres Rheumatol. 2000; 14: 715-29.

https://doi.org/10.1053/berh.2000.0109

3. Reyes-Lierena GA, Guibert - Toledano M, Cardiel MA, Prevalence \& Barden of Rheumatic diseases in Cuba. A COPCORD study. J clin Rheumatol. 2009; 15 (2): 51-5.

https://doi.org/10.1097/RHU.0b013e31819b61cb

PMid:19265344.

4. Chaiamnuay P, Darmawan J, Muirden KD, Assawatana bodee P. Epidemiology of rheumatic diseases in rural Thailand: a WHO-ILAR-COPCORJD study. Community Oriented Program for the Control of Rheumatic Disease. J Rheumatol. 1998; 25: 1382-7.

5. Dans LF, Tankeh-Torres S, Amante CM, Penserga EG. The prevalence of rheumatic disease in a Filipino urban population; a WHO-ILAR-COPCORD study. J Rheumatol.1997; 24: 1814-9.

https://doi.org/10.1016/S0895-4356(98)90015-4

6. Darmawan J, Volkenburg HA, Muirden KD, Wigley $\mathrm{RD}$. Epidemiology of rheumatic disease in rural and urban Indonesia: a WHO-ILAR-COPCORD study, stage -1, phase- 2.Ann rheum dis. 1992; 51: 525-8.

https://doi.org/10.1136/ard.51.4.525

PMid:1586254 PMCid:PMC1004706.

7. S.A. Haq, Darmawan John, Islam MN. Prevalence of rheumatic diseases and associated outcomes in rural and urban communities in Bangladesh: A COPCORD study. J Rheumatol. 2005; 32: 348-353. 